\title{
Functions, disabilities and perceived health in the first year after total knee arthroplasty; a prospective cohort study
}

\author{
Danielle D. P. Berghmans ${ }^{1,4^{*}}$ (D) Antoine F. Lenssen ${ }^{1,4}$, Pieter J. Emans ${ }^{2,4}$ and Rob A. de Bie 3,4
}

\begin{abstract}
Background: In end-stage knee osteoarthritis total knee arthroplasty (TKA) is an effective intervention to reduce pain and improve functioning in the majority of patients. However, after TKA some patients still experience pain, loss of function, deficient muscle strength or reduced walking speed. This study systematically assesses patients' functions, disabilities and health before TKA and at short- (3 months) and long-term (12 months) on all International Classification of Functioning, Disability and Health domains.

Methods: In this prospective cohort study 150 patients underwent the following tests before and at 3 and 12 months after surgery: Western Ontario and McMaster Universities Arthritis Index, Short Form 12, Knee Society Score, Patient Specific Functioning Scale, knee range of motion, quadriceps and hamstring strength, gait parameters, global perceived effect (only after surgery). All data was analyzed with repeated measures ANOVA for all measurement time points.

Results: Despite increased gait speed, quadriceps strength and scores on questionnaires being above pre surgical levels, patients do not reach levels of healthy persons. Walking speeds approach normal values and are higher in our study compared with the literature. Quadriceps strength stays at around 70 till $80 \%$ of norm values. However, dissatisfaction rates are below 10\%, which is low compared to the literature.

Conclusions: Quality of life, activities, muscle strength and gait parameters improve significantly after TKA. However, some complaints regarding activities and walking speed remain. Most striking outcome is the remaining deficit in quadriceps strength.
\end{abstract}

Keywords: Osteoarthritis, TKA, Total knee arthroplasty

\section{Background}

Osteoarthritis (OA) is one of the ten most disabling diseases in developed countries: $9.6 \%$ of all men and 18.0\% of all women over 60 years of age have symptomatic osteoarthritis [1]. While pain is the most prominent symptom, $80 \%$ of these patients have limitations in movement, and $25 \%$ cannot perform daily activities [1]. An increase in prevalence is expected due to ageing and obesity $[1-5]$.

\footnotetext{
*Correspondence: danielle.berghmans@mumc.nl

'Department of Physical therapy, Maastricht University Medical Center +, PO 5800, 6202, AZ, Maastricht, The Netherlands

${ }^{4}$ Maastricht University/CAPHRI School for Public Health and Primary Care, P.O. Box 616, 6200, MD, Maastricht, The Netherlands

Full list of author information is available at the end of the article
}

In end-stage osteoarthritis, joint replacement is an effective intervention to reduce pain and improve functioning in the majority of patients [3, 6-9]. However, it has been reported that $15-30 \%$ of patients still experience pain and loss of function after total knee arthroplasty (TKA) [7, 9-12].

Several studies have investigated recovery after TKA. Although most describe a 10-20\% improvement in quadriceps strength and gait parameters in comparison to the pre-operative status, values remained lower than in healthy peers or the uninvolved leg [11-19]. A correlation between quadriceps strength and functional performance after TKA $[18,19]$ seems logical, for functional performance can be assumed to improve with quadriceps strength. Several studies found improvements in patient-reported

(c) The Author(s). 2018 Open Access This article is distributed under the terms of the Creative Commons Attribution 4.0 International License (http://creativecommons.org/licenses/by/4.0/), which permits unrestricted use, distribution, and reproduction in any medium, provided you give appropriate credit to the original author(s) and the source, provide a link to the Creative Commons license, and indicate if changes were made. The Creative Commons Public Domain Dedication waiver (http://creativecommons.org/publicdomain/zero/1.0/) applies to the data made available in this article, unless otherwise stated. 
outcome measures (PROMs), functional status and quality of life. [12-14, 20, 21]. However, patients often did not regain optimal health [22]. No relation with strength is investigated in these studies.

Although several studies investigated aspects of recovery after TKA, no study yet has incorporated all domains of the International Classification of Functioning, Disability and Health (ICF) in their assessment. Interesting findings in the ICF domains may be missed by the limited follow-up, population size and incompleteness of ICF domains of other studies. We therefore performed a prospective cohort study in which 150 patients scheduled for TKA were followed till 1 year after surgery, and in which we systematically assessed all domains of the ICF. Our first objective was to provide a more complete overview of current physical recovery rates of patients with TKA in the first year after surgery in the Netherlands. We hypothesize that the patients in our study will improve on all parameters in the first year after surgery. Our second objective is to generate normative quadriceps and hamstrings strength values for patients receiving a TKA in the Netherlands.

\section{Methods}

\section{Study design}

This prospective cohort study assessed all patients with the same set of measurement instruments during personal follow-up consultations at three time points before and after surgery. We chose as an endpoint a follow-up time of 1 year, as no further major improvement can be expected after this time period [7, 23].

\section{Patients}

Between March 1, 2011 and March 1, 2013, all consecutive patients with knee osteoarthritis scheduled for a TKA at the osteoarthritis clinic of Maastricht University Medical Centre (MUMC+) were informed about the study in writing and verbally at least 1 week before the planned surgery. On the day before surgery, when patients arrived at the hospital, they were contacted by the researcher, and written informed consent was obtained.

At the start of the study, we performed a sample size calculation. Based on the number of determinants and the pragmatic rule of thumb to include ten cases for each determinant we would need at least 120 cases to obtain adequate power $(10 \times 12$ determinants $=120)$. Since we expected a lost of follow up of $15 \%$ we would need 140 subjects. To be on the safe side we included 10 patients more $(N=150)$.

Inclusion criteria were: Dutch speaking patients between 18 and 80 years at the time of surgery, diagnosed with knee osteoarthritis for which primary TKA was indicated. Patients were excluded if they underwent a unicondylar knee arthroplasty (UKA), had a neurological problem influencing ambulation or had an immobile hip or ankle arthrodesis. Severe comorbidities were excluded since all patients had to be eligible for surgery.

The local medical ethics committee of the MUMC+ reviewed and approved the study (NL33015.068.10 / METC 10-2-083). The rights of the subjects were protected under the Helsinki Declaration.

\section{Surgery}

All patients received a cemented Scorpio or Scorpio NRG TKA (Stryker, Kalamazoo, Michigan, USA). After performing a medial parapatellar approach a bony referenced, tibia first technique was used. A tourniquet was only used during the cementation period of the prosthesis. A previous study reported no differences in Range of Motion (ROM), function or Quality of Life between these to prosthesis [24].

\section{Procedure}

After signing informed consent, patients were enrolled in the cohort study. All assessments were performed by the research team the day before surgery and 3 and 12 months after surgery. We chose these time points because of scheduled appointments, enabling us to have personal contact with the patients without involving extra travel time. The patients were not shown the answers or the values obtained in previous sessions.

\section{Measurements}

In addition to the demographic patient characteristics (age, sex, height and weight), the following questionnaires and measurements were performed by a research team using a standardized protocol.

\section{Health status questionnaires}

The Western Ontario and McMaster Universities Osteoarthritis Index (WOMAC) is a self-administered disease-specific health questionnaire designed to measure the functional ability of the osteoarthritic hip and knee [25]. The WOMAC provides aggregate scores for each of three subscales: joint pain, joint stiffness and function. The WOMAC is a responsive instrument that yields reliable and valid measurements in patients with hip and knee osteoarthritis and has been extensively used to evaluate this patient population [9, 25-27]. The 5-point Likert version of this measure was used in our study. The scale was transformed to a range from 0 to 100 points (100 being the best score).

The Patient Specific Functional Scale (PSFS) records patients' perceptions of their disabilities [28]. Patients define their main complaints (i.e. difficulties performing certain activities) and rate the difficulty of performance on an 11-point numerical rating scale (NRS) $(10=$ no 
problems; $0=$ impossible) [28] The three main complaints had to be defined as specifically as possible, and had to cause difficulties related to the osteoarthritis of the knee. The PSFS is a reliable and responsive measure in this population, $[29,30]$ and its validity has been confirmed in a population of patients with knee problems [29].

The Knee Society Score (KSS) is a knee-joint specific questionnaire and consists of two parts: a knee score $(0-100,100$ being the best score) and a function score $(0-100,100$ being the best score) [31]. The KSS is a valid and responsive measure in a population of patients after TKA [32].

The Short Form 12 (SF12) is a generic multidimensional questionnaire measuring quality of life from a patient's perspective. It is a short version of the SF36 and includes two components (physical and mental health), representing these respective domains (scale $0-100,100$ being the best score). It is a valid, reliable and responsive measure in a general population and easy to administer [33].

The global perceived effect (GPE) is a 2-item scale on which patients can rate their overall recovery since a predefined point (in this study pre-surgical function) in time and their satisfaction with the treatment, on 7-point Likert scales (ranging from 2 [satisfied] to 14 [dissatisfied]). Its reliability and validity are good in patients with musculoskeletal disorders [34].

\section{Physical performance tests}

Muscle strength was assessed with a Biodex ${ }^{\circ}$ System 3 Pro dynamometer (Biodex System 3 Pro Dynamometer, Biodex Medical Systems, Inc., Biodex Medical Systems, USA). Isokinetic strength $\left(60^{\circ} / \mathrm{s}\right.$ and $180^{\circ} / \mathrm{s}$, in $\left.\mathrm{Nm}\right)$ of the quadriceps and the hamstrings was measured using respectively five and ten repetitions. The peak volitional values were used in the analysis. The Biodex ${ }^{\circ}$ is a reliable and valid isokinetic dynamometer [35].

$R O M$ was measured with a long-arm goniometer, (Goniometer, Long Arm, Gymna, Belgium), according to Lenssen et al. [36] Extension and flexion were measured in supine position, with hyperextension noted as a positive value. Measuring ROM with a long-arm goniometer has been reported to be valid and reliable at group level [36].

The gait parameters of step length and walking speed were measured with the GAITRite ${ }^{\circ}$ system (CIR systems, PA, USA), a highly valid and reliable tool to assess temporospatial gait parameters in patients undergoing a TKA [37].

\section{Statistical analyses}

Analyses were performed with SPSS for Windows version 23. [38] Means and standard deviations were calculated to describe characteristics. Repeated Measures ANOVA were performed to test for significant differences between baseline till 3 months after surgery and between 3 and 12 months after. A significance level of $p$ $<.05$ was used. A Bonferroni correction was used to correct for multiple testing.

Patients who dropped out during the test period were not replaced. All available data was analyzed; in case data was missing, the mean value of the parameter at that time point was imputed.

We also compared the strength of the quadriceps and hamstrings measured in our population with that of controls. We built a norm data set, consisting of 245 patients, 166 women (mean age 58.4 years [10.1], weight $69.6 \mathrm{~kg}$ [10.9]) and 129 men (56.2 years [10.7], weight $83.9 \mathrm{~kg}$ [10.6]). We tested their isokinetic quadriceps and hamstrings strength at an angular speeds of $60 \%$ and $180^{\circ} / \mathrm{s}$. We calculated formulas (Table 1 ) for both sexes in both angular speeds for the quadriceps and hamstrings. These formulas were used to calculate the mean norm values for our population. These values and the percentage of the norm values are presented.

\section{Results}

Between March 1, 2011 and March 1, 2013, we included 150 patients, 71 men and 79 women, with a mean age of $64.7 \pm 8.0$ years. The majority of patients had surgery of the right knee (right 89, left 61) and mean BMI was $31.2 \mathrm{~kg} / \mathrm{m}^{2}$ for men and $30.7 \mathrm{~kg} / \mathrm{m}^{2}$ for women (Table 2). We lost 4 patients at 3-months follow-up and an additional 3 at the 12-month measurement. Not all patients were able to come to the hospital for the follow-up measurements, so data on physical tests (strength, temporospatial gait parameters and ROM) were unavailable for 7 patients at 3-months and for 9 patients at the 12-month measurement (4 of whom were the same as those at the three-month measurement).

With the exception of the SF12, patients improved significantly on all questionnaires over 3 and 12 months. The largest improvement occurred within the first 3 months. The largest and significant improvement of the SF12 Physical component was only between baseline and 3 months (Table 3 ).

Table 1 Isokinetic strenght formula

\begin{tabular}{|c|c|c|c|}
\hline & & Men & Women \\
\hline \multirow[t]{2}{*}{ Quadriceps } & $60 \% / s$ & $305-2,67 \times$ age & 172-1,42×age \\
\hline & $180^{\circ} / \mathrm{s}$ & 207-1,96xage & 108-0,94xage \\
\hline \multirow[t]{2}{*}{ Hamstrings } & $60 \% / \mathrm{s}$ & 193-1,66×age & 116-1,01×age \\
\hline & $180^{\circ} / \mathrm{s}$ & 149-1,36xage & 89-0,81×age \\
\hline
\end{tabular}

Table 1 shows the fomula for calculating the isokinetic strength for a healthy population. Age in years 
Table 2 Patient Characteristics

\begin{tabular}{lll}
\hline & Men & Women \\
\hline Age $(\mathrm{y})(\mathrm{sd})$ & $64.2(8.8)$ & $65.1(7.4)$ \\
Height $(\mathrm{m})(\mathrm{sd})$ & $1.75(0.06)$ & $1.66(0.06)$ \\
Weight $(\mathrm{Kg})(\mathrm{sd})$ & $95.7(13.6)$ & $84.6(15.5)$ \\
Body Mass $\mathrm{Index}\left(\mathrm{Kg} / \mathrm{m}^{2}\right)(\mathrm{sd})$ & $31.2(4.2)$ & $30.7(5.5)$ \\
\hline
\end{tabular}

Age, height, weight and body mass index for men and women. $s d$ standard deviation

The GPE is shown in Fig. 1. After 3 months, $5.3 \%$ of all patients reported to have fully recovered from surgery, and after 1 year $25.3 \%$ did so. After 3 months, $2.7 \%$ of all patients were totally dissatisfied with the result and the treatment, against $1.3 \%$ after 1 year. Overall, the majority of patients were satisfied with the result, but had some residual complaints.

Figure 2 and 3 show respectively the $60 \%$ s isokinetic quadriceps and hamstrings muscle strength in the peri-operative phase of men and women. After 3 months the quadriceps isokinetic strength measured at $60 \% \mathrm{~s}$ speed is back on pre-surgical level for women (baseline 43.4 Nm [27.8]; 3 months $46.1 \mathrm{Nm}$ [17.1]; significance 1.000) and for men (baseline 67.9 Nm [35.5]; 3 months $73.3 \mathrm{Nm}$ [26.2]; significance 0.521). The quadriceps $180^{\circ} /$ s only improved significantly in men in 33 months (baseline 43.3 Nm [23.0]; 3 months $50.5 \mathrm{Nm}$ [17.4]; significance 0.005), women were back on pre-surgical level (baseline 29.2 Nm [16.4]; 3 months $30.0 \mathrm{Nm}$ [11.7]; significance 1.000). Over 12 months a significant improvement was demonstrated, at both angular speeds and for both sexes (women 60\% $64.5 \mathrm{Nm}$ [18.9] 180\% 38.2 [11.8]; men $60^{\circ} / \mathrm{s}: 95.2 \mathrm{Nm}$ [30.5] $180^{\circ} / \mathrm{s}: 61.8$ [19.1]). 60 $\%$ Isokinetic Hamstrings strength in men and women

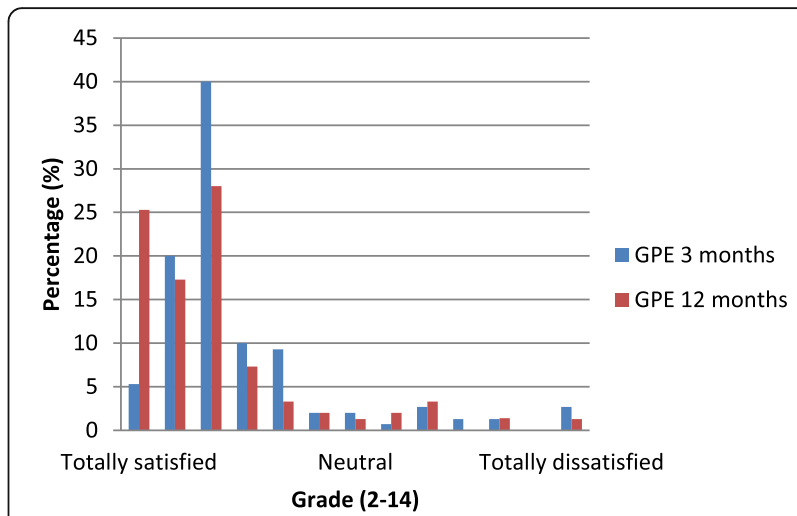

Fig. 1 shows the Global Perceived Effect scores 3 and 12 months after TKA, with percentages. GPE; Global Perceived Effect

improved significantly in the first year after surgery, compared to pre-surgical values (women; baseline $33.3 \mathrm{Nm}$ [18.9]; 3 months $39.8 \mathrm{Nm}$ [16.7]; significance 0.009; 12 months $50.7 \mathrm{Nm}$ [16.2]; significance 0.000; men; baseline $48.0 \mathrm{Nm}$ [23.4]; 3 months $65.6 \mathrm{Nm}$ [22.8]; significance 0.000; 12 months $77.2 \mathrm{Nm}$ [26.1]; significance 0.000$) .180^{\circ} / \mathrm{s}$ Isokinetic Hamstrings strength only improved significant in in men in both time periods (baseline 37.8 Nm [18.6]; 3 months $47.1 \mathrm{Nm}$ [17.8]; significance 0.000; 12 months 54.4 Nm [20.9]; significance 0.002 . and in women only between 3 and 12 months (baseline 24.4 Nm [12.6]; 3 months $27.1 \mathrm{Nm}$ [11.3]; significance $0.263 ; 12$ months $33.3 \mathrm{Nm}$ [11.6]; significance 0.000.)

We also compared muscle strength of our patients with that of healthy individuals. At baseline, our patients had 51.6 to $63.3 \%$ of the quadriceps strength of healthy persons, and $56.8-69.5 \%$ of the hamstrings strength. At

Table 3 Questionnaires

\begin{tabular}{|c|c|c|c|c|c|}
\hline & \multirow[t]{2}{*}{ Baseline } & \multicolumn{2}{|l|}{3 months } & \multicolumn{2}{|l|}{12 months } \\
\hline & & & sig. & & sig. \\
\hline Short Form - 12; Physical (sd) & $33.5(7.9)$ & $38.8(7.7)$ & 0.000 & $39.3(9.2)$ & 1.000 \\
\hline Short Form - 12; Mental (sd) & $44.7(10.6)$ & $45.0(9.6)$ & 1.000 & $46.4(9.2)$ & 0.164 \\
\hline WOMAC Pain (sd) & $10.6(4.1)$ & $16.0(4.1)$ & 0.000 & $17.6(4.4)$ & 0.000 \\
\hline WOMAC Stifness (sd) & $4.1(1.9)$ & $4.9(1.9)$ & 0.000 & $5.8(1.9)$ & 0.000 \\
\hline WOMAC Function (sd) & $39.0(12.3)$ & $54.4(13.0)$ & 0.000 & $58.2(12.9)$ & 0.000 \\
\hline WOMAC Total (sd) & $54.1(16.2)$ & $75.4(17.6)$ & 0.000 & $81.7(18.0)$ & 0.000 \\
\hline PSFS 1 (sd) & $1.9(2.0)$ & $2.8(3.4)$ & 0.000 & $6.6(3.7)$ & 0.000 \\
\hline PSFS 2 (sd) & $2.2(2.1)$ & $4.8(3.6)$ & 0.000 & $6.8(3.4)$ & 0.000 \\
\hline PSFS 3 (sd) & $2.4(2.4)$ & $4.9(3.6)$ & 0.000 & $6.9(3.4)$ & 0.000 \\
\hline Knee Society Score; Knee (sd) & $52.5(16.4)$ & $76.1(17.3)$ & 0.000 & $84.1(17.5)$ & 0.000 \\
\hline Knee Society Score; Function (sd) & $57.2(13.1)$ & $69.4(15.4)$ & 0.000 & $74.8(18.5)$ & 0.000 \\
\hline
\end{tabular}

$N$ number, sd standard deviation, WOMAC Western Ontario and McMaster Universities Osteoarthritis Index, PSFS Patient Specific Functional Complaint, Sig p-value The scores on the questionnaires are given at baseline and 3 and 12 months after surgery. Significance of progression from baseline to 3 months and from 3 till 12 months 


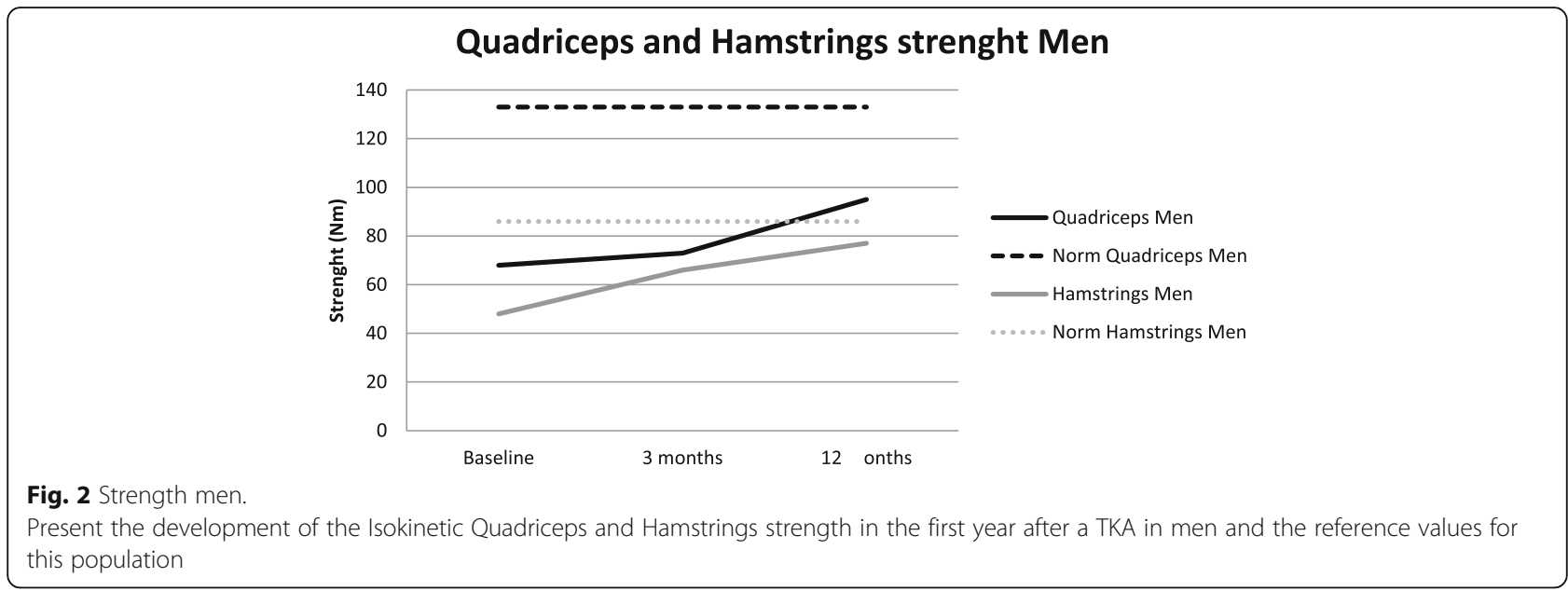

3 months, values were 55.7 to $64.4 \%$ of the quadriceps and $76.1-79.5 \%$ of the hamstrings, respectively, and at 12 months 72.0 to $81.7 \%$ and 88.4 to $100.7 \%$, respectively.

Table 4 lists the ROM values. The mean baseline flexion was $120^{\circ}$. Flexion was limited immediately after surgery, but increased again during the first weeks. After three months, flexion had returned almost to baseline value, although there was still a significant difference. At 12 months, the flexion had returned to baseline level. Overall, extension ROM did not change significantly after a TKA.

Table 5 shows walking speed and step length. The step length of the healthy and surgical leg increased significantly over time. With increasing step length, walking speed also increased significantly over time after TKA $(98.9 \mathrm{~cm} / \mathrm{s}$ at baseline, $108.4 \mathrm{~cm} / \mathrm{s}$ at 3 months and $117.0 \mathrm{~cm} / \mathrm{s}$ at 12 months). Improvement of walking speed between baseline and the 3-month measurement was comparable to that between the 3- and 12-month measurements. The largest improvement in step length was between baseline and 3-month measurements.

\section{Discussion}

This study reports on the first year of physical recovery of patients undergoing a TKA in the Netherlands and could therefore be useful in informing patients about prognostic consequences of a TKA.

The most remarkable finding in this study is the persistent limited muscle strength. Whilst other outcome measures improved to nearly normal values compared to the healthy population, quadriceps strength lagged behind. Before surgery, strength was half of that of matched healthy persons, a higher deficit than reported in the literature $[12,15]$. Three months after surgery, mean strength was comparable to pre-surgical values. Although strength increased from 3 till 12 months after TKA, it never reached 'healthy' values. We do not expect that pain has a role in the muscle strength deficit since a large amount of patient did not experienced pain during strength measurement after the surgery, in contrast with the measurement pre-surgically. One reason could be the changed kinematics of the knee (altered patellofemoral kinematics) and/or muscle loss due to surgery. A change in strength was seen in an in vitro study by

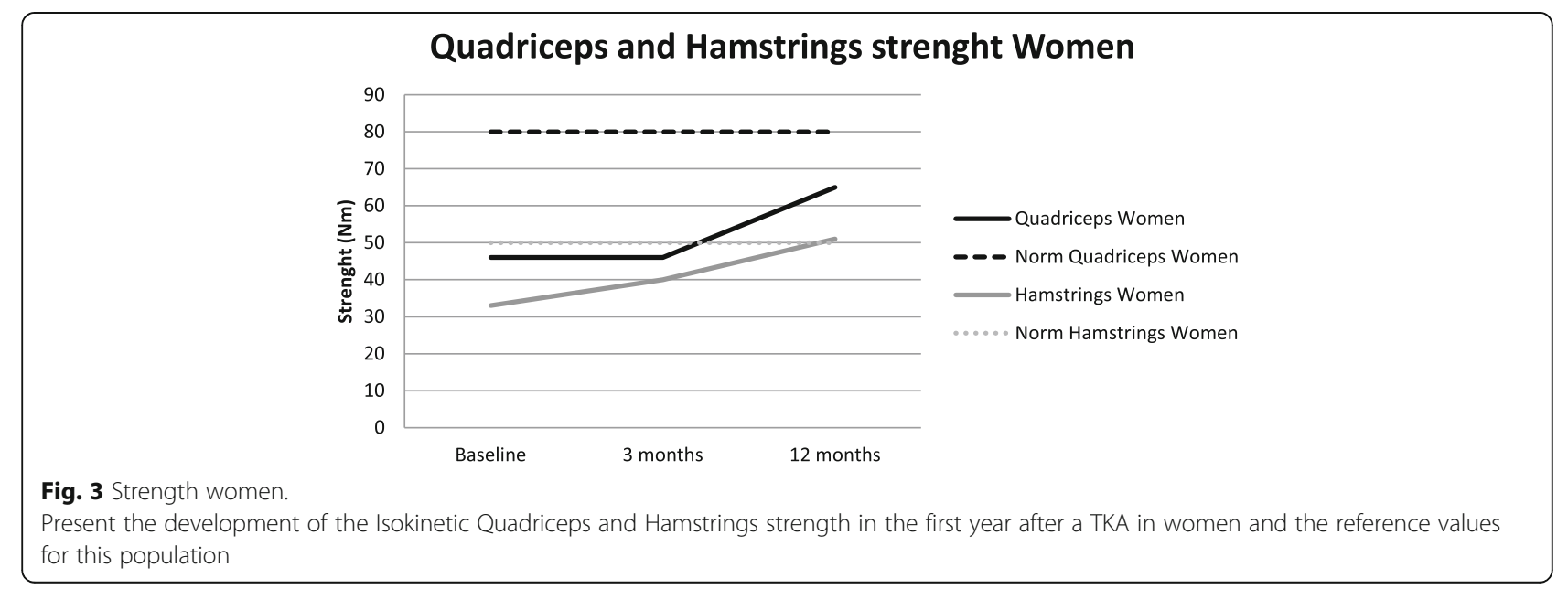


Table 4 ROM

\begin{tabular}{|c|c|c|c|c|c|}
\hline & \multirow[t]{2}{*}{ Baseline } & \multicolumn{2}{|l|}{3 months } & \multicolumn{2}{|l|}{12 months } \\
\hline & & & sig. & & sig. \\
\hline Flexion $\left({ }^{\circ}\right)(s d)$ & $120.1(12.6)$ & $114.9(13.7)$ & 0.001 & $120.6(14.7)$ & 0.000 \\
\hline Extension $\left({ }^{\circ}\right)(\mathrm{sd})$ & $-2.3(5.7)$ & $-2.5(5.3)$ & 1.000 & $-1.3(5.7)$ & 0.085 \\
\hline
\end{tabular}

$n$ number, Sig. $p$-value

Flexion and extension values prior to surgery and 3 and 12 months after

surgery, in degrees. Significance of progression from baseline to 3 months and from 3 till 12 months

Ostermeier et al., who compared hinged and non-hinged TKAs [39]. Further, during therapy focus is on functional training and isokinetic strength measurement is not performed standardly. Our large study population underlined the muscle deficit already reported in other studies with a smaller sample size [12, 15-19]. In these studies even a higher deficit was described 3 months after surgery [12, 18]. Further, the total gain in muscle strength in the first year was higher in our study compared to the literature [15]. This could be due to the larger improvement in the first months compared with the literature. A reason could be the health care system in the Netherlands. The main part of all patients receive routinely a prescription for physical therapy after the TKA surgery for 1 year physical therapy. Generally, they have therapy twice a week. This could result in a faster and larger improvement of muscle strength which focuses on activity level, like walking with and without crutches and walking stairs. This is in contrast with the amount of physical therapy patients receive in other countries worldwide. Bade et al. described only that $26 \%$ of all patients receive outpatient physical therapy [12]. This could also possibly explain the smaller deficit of walking speed in our study. Walking speed in our pre-surgical $[12,13]$ and post-surgical patients is higher than reported in the literature in which patients with a TKA walked $20 \%$ more slowly than healthy individuals 1 year after surgery $[8,13,17]$. Before surgery, the walking speed of patients in our study $(98,9 \mathrm{~cm} / \mathrm{s})$ was $20.0-$ $26.1 \%$ lower than in a healthy population (healthy walking speed for women [60-69 years] $1.24 \mathrm{~m} / \mathrm{s}$ and for men [60-69 years] $1.34 \mathrm{~m} / \mathrm{s}$ ) [40]. After surgery, walking speed $(108.4 \mathrm{~cm} / \mathrm{s})$ increased but remained lower than in healthy persons (between $81.0-87.3 \%$ of the healthy walking speed) [40]. After 12 months, walking speed
$(117.0 \mathrm{~cm} / \mathrm{s})$ still increased, but did not reach the healthy level (attaining between 87.3 and $94.2 \%$ of the walking speed of healthy individuals). However, in terms of managing pedestrian street crossings with lights (which are designed for $1.2 \mathrm{~m} / \mathrm{s}$ ), $81 \%$ of our population were unable to cross the street safely before their surgery. After 3 months, this percentage had decreased to $65 \%$, but after 12 months it was still $49 \%$.

Pua et al. [41] investigated the relationship between walking speed and physical parameters in the first 16 weeks after TKA. They found ipsilateral quadriceps strength as strongest predictor for walking speed. No linear relationship existed till $111 \mathrm{~N}$, a steep rise in gait speed was observed with every gain in muscle strength. After 111 Newton the speed increased more gradually [41]. However, according to Alnahdi et al. [42], the influence of quadriceps strength on gait patterns is only moderate till 6 months and in the period till 1 year it even decreases.

All questionnaires regarding level of functioning, quality of life and patient-specific complaints yielded lower scores compared to healthy controls, both pre- and postsurgical. (For healthy peers, we assumed highest possible score on the WOMAC, KSS and PSFS [related to knee problems] may be expected. For the SF12 we used reference data from the United states of America in which the healthy population had a score on the mental part of 51.6 and 43.9 on the physical part [43]). However, a large and significant increase was reported on all questionnaires over the 12 months following surgery. This is in agreement with previous studies $[4,9,12-15,18,20-$ 22]. Only, our population seemed to recover faster; they performed on pre-surgical level at 3months, while in other studies this took about 6 months [12]. Again, this could be due to the amount of physical therapy in the Netherlands, focused on activities like walking, walking stairs and making transfers.

Possible due to the faster increase in strength, walking speed and questionnaires, our patients were more satisfied compared to those in other studies, as seen on the GPE (8.7\% dissatisfied at 3 months, $7.9 \%$ dissatisfied at 12 months, whereas in other studies $15-30 \%$ of the patients were dissatisfied) [7, 9-12]. However, a relation between satisfaction and improvement in pain, function and handicap is difficult, and therefore, according to

Table 5 Walking speed and step length

\begin{tabular}{|c|c|c|c|c|c|c|}
\hline & & \multirow[t]{2}{*}{ Baseline } & \multicolumn{2}{|l|}{3 months } & \multicolumn{2}{|l|}{12 months } \\
\hline & & & & sig. & & sig. \\
\hline \multicolumn{2}{|c|}{ Walking speed $(\mathrm{cm} / \mathrm{s})(\mathrm{sd})$} & $98.9(23.3)$ & $108.4(19.9)$ & 0.000 & $117.0(19.9)$ & 0.000 \\
\hline \multirow[t]{2}{*}{ Step lenght } & Surgical leg (cm) (sd) & $57.6(11.2)$ & $61.9(8.3)$ & 0.000 & $64.1(8.5)$ & 0.000 \\
\hline & Healthy leg (cm) (sd) & $58.0(9.9)$ & $62.2(8.6)$ & 0.000 & 64.8 (8.7) & 0.000 \\
\hline
\end{tabular}

$n$ number, Sig. $p$ - value

Walking speed and step length pre-surgical and 3 and 12 months after TKA with the significance level 
Genet et al. satisfaction should be investigated as an independent parameter [14].

Nonetheless, patients' physical capability can be satisfying, their spare capacity could be less, giving a higher risk for frailty in case of a trauma or hospitalization. Therefore, despite of the importance of their satisfaction as success indicator for surgery, measuring their functional activity level is an important indicator.

\section{Limitations}

We decided to use performance tests to assess functions and questionnaires to measure activities, so the results regarding activities are from the patients' view and could therefore be subjective.

Another limitation is that we do not have information about osteoarthritis in other joints of the patients. Which might have an influence on the functional performance.

Our findings confirm that a TKA improves quality of life for patients with knee osteoarthritis and can be used to inform patients about possible prognostic consequences of a TKA, which is imported in patient-centered care. However, patients do not reach the values attained by healthy persons, and complaints persist in the first year after surgery. Quadriceps strength in particular remains limited, which may be a reason for persistent complaints. In our opinion most muscle deficits are not noticed during daily activities. However, in case of illness of (surgical) stress patients have less spare capacity and will have a higher chance to become frail. Physical therapy focuses on ROM and daily activities, but testing and training quadriceps strength until normal values are attained (if possible) is an important part of the therapy. As mentioned earlier, further research should focus on the effect of more progressive resistance training on the remaining muscle strength deficits in the first year after TKA. Besides this, further investigation in pathophysiology of muscle weakness is necessary.

\section{Conclusions}

Quality of life, activities, muscle strength and gait parameters improve significantly after a TKA. However, complaints on activities and walking speed remain. Most striking was the limited quadriceps strength, which we believe may restrict patients in daily life. Therefore, future studies should address the impact of strength training after a TKA on the improvement in muscle strength and daily activities.

\footnotetext{
Abbreviations

GPE: Global Perceived Effect; ICF: International Classification of Functioning, Disability and Health; KSS: Knee Society Score; MUMC: Maastricht University Medical Centre; OA: Osteoarthritis; PROM: Patient-Reported Outcome Measures; PSFS: Patient Specific Functional Scale; ROM: Range of Motion; SF12: Short Form 12; TKA: Total Knee Arthroplasty; UKA: Unicondylar Knee Arthroplasty; WOMAC: Western Ontario and McMaster Universities Osteoarthritis Index
}

\section{Acknowledgements}

We would like to thank the following persons for their contributions to this study: Nick Coenen, Lotte van Delft, Simone Engels, Anja Großek, Aniek Heldens, Peter Hilgers, Elena Issigonis, Ramon Janssen, Patrick Lebeck, Michael Leroy, Dennis Linden, Maarten Neuhaus, Laura Niggebrugge, Hugo van Nuland, Hannah Pallubinski, Ineke Salemans, Pia Stadler, Sanne Vijgen, Marwin Weber and Mandy Welters.

\section{Funding}

This research did not receive any specific grant from funding agencies in the public, commercial, or not-for-profit sectors.

\section{Availability of data and materials}

The dataset used and analyzed during the current study is available from the corresponding author on reasonable request.

\section{Authors' contributions \\ Study conception and design: DB, AL, RB. Acquisition of data: DB, AL. Analysis and interpretation of the data: $\mathrm{DB}, \mathrm{AL}, \mathrm{RB}, \mathrm{PE}$. Drafting of the manuscript: DB. Critical revision: AL, RB, PE. Read and approved the manuscript: $\mathrm{DB}, \mathrm{AL}, \mathrm{RB}, \mathrm{PE}$}

\section{Ethics approval and consent to participate}

The local medical ethics committee of the Maastricht University Medical Centre reviewed and approved the study procedures (NL33015.068.10 / METC 10-2-083). Written informed consent was obtained from all patients. The rights of subjects were protected under the Helsinki Declaration.

\section{Consent for publication}

Not applicable.

\section{Competing interests}

The authors declare that they have no competing interests.

\section{Publisher's Note}

Springer Nature remains neutral with regard to jurisdictional claims in published maps and institutional affiliations.

\section{Author details}

'Department of Physical therapy, Maastricht University Medical Center +, PO 5800, 6202, AZ, Maastricht, The Netherlands. 'Department of Orthopedics, Maastricht University Medical Center +, PO 5800, 6202, AZ, Maastricht, The Netherlands. ${ }^{3}$ Department of Epidemiology, Maastricht University, P.O. Box 616, 6200, MD, Maastricht, The Netherlands. ${ }^{4}$ Maastricht University/CAPHRI School for Public Health and Primary Care, P.O. Box 616, 6200, MD,

Maastricht, The Netherlands.

Received: 22 December 2017 Accepted: 27 June 2018

Published online: 25 July 2018

\section{References}

1. Chronic rheumatic conditions [http://www.who.int/chp/topics/rheumatic/ en/]. Accessed 26 Feb 2018.

2. Köke A, van den Ende C, Jansen M, Steultjens M, Veenhof C: KNGFstandaard Beweeginterventie Artrose. 2008.

3. Kennedy DM, Stratford PW, Riddle DL, Hanna SE, Gollish JD. Assessing recovery and establishing prognosis following total knee arthroplasty. Phys Ther. 2008;88(1):22-32.

4. Papakostidou I, Dailiana ZH, Papapolychroniou T, Liaropoulos L, Zintzaras E, Karachalios TS, Malizos KN. Factors affecting the quality of life after total knee arthroplasties: a prospective study. BMC Musculoskelet Disord. 2012;13(1):116.

5. Priority Medicines for Europe and the World 2013 Update [http://www.who. int/medicines/areas/priority_medicines/Ch6_120steo.pdf]. Accessed 26 Feb 2018.

6. Beers MH, Berkow R. The Merck manual, vol. 2: Bohn Stafleu Van Loghum; 2003.

7. Zeni JA Jr, Snyder-Mackler L. Early postoperative measures predict 1- and 2year outcomes after unilateral total knee arthroplasty: importance of contralateral limb strength. Phys Ther. 2010;90(1):43-54. 
8. Mizner RL, Petterson SC, Stevens JE, Axe MJ, Snyder-Mackler L. Preoperative quadriceps strength predicts functional ability one year after total knee arthroplasty. J Rheumatol. 2005;32(8):1533-9.

9. Jones CA, Voaklander DC, Suarez-Alma ME. Determinants of function after total knee arthroplasty. Phys Ther. 2003;83(8):696-706.

10. Bourne RB, Chesworth BM, Davis AM, Mahomed NN, Charron KD. Patient satisfaction after total knee arthroplasty: who is satisfied and who is not? Clin Orthop Relat Res. 2010;468(1):57-63.

11. Yoshida Y, Mizner RL, Ramsey DK, Snyder-Mackler L. Examining outcomes from total knee arthroplasty and the relationship between quadriceps strength and knee function over time. Clin Biomech. 2008;23(3):320-8.

12. Bade MJ, Kohrt WM, Stevens-Lapsley JE. Outcomes before and after total knee arthroplasty compared to healthy adults. J Orthop Sports Phys Ther. 2010;40(9):559-67.

13. Bolink S, Grimm B, Heyligers I. Patient-reported outcome measures versus inertial performance-based outcome measures: a prospective study in patients undergoing primary total knee arthroplasty. Knee. 2015;22(6):618-23

14. Genet F, Schnitzler A, Lapeyre E, Roche N, Autret K, Fermanian C, Poiraudeau S. Change of impairment, disability and patient satisfaction after total knee arthroplasty in secondary care practice. Ann Readapt Med Phys. 2008;51(8):671-6. 676-682

15. Meier W, Mizner R, Marcus R, Dibble L, Peters C, Lastayo PC. Total knee arthroplasty: muscle impairments, functional limitations, and recommended rehabilitation approaches. J Orthop Sports Phys Ther. 2008;38(5):246-56.

16. Rossi MD, Hasson S. Lower-limb force production in individuals after unilateral total knee arthroplasty. Arch Phys Med Rehabil. 2004;85(8): 1279-84.

17. Walsh M, Woodhouse LJ, Thomas SG, Finch E. Physical impairments and functional limitations: a comparison of individuals 1 year after total knee arthroplasty with control subjects. Phys Ther. 1998;78(3):248-58.

18. Mizner RL, Petterson SC, Snyder-Mackler L. Quadriceps strength and the time course of functional recovery after total knee arthroplasty. J Orthop Sports Phys Ther. 2005;35(7):424-36.

19. Silva $M$, Shepherd EF, Jackson WO, Pratt JA, McClung CD, Schmalzried TP. Knee strength after total knee arthroplasty. J Arthroplast. 2003;18(5): 605-11.

20. Dailiana ZH, Papakostidou I, Varitimidis S, Liaropoulos L, Zintzaras E, Karachalios T, Michelinakis E, Malizos KN. Patient-reported quality of life after primary major joint arthroplasty: a prospective comparison of hip and knee arthroplasty. BMC Musculoskelet Disord. 2015;16(1):1.

21. Poortinga S, Van den Akker-Scheek I, Bulstra SK, Stewart RE, Stevens M. Preoperative physical activity level has no relationship to the degree of recovery one year after primary Total hip or knee arthroplasty: a cohort study. PLoS One. 2014;9(12):e115559.

22. Finch $E$, Walsh $M$, Thomas SG, Woodhouse LJ. Functional ability perceived by individuals following total knee arthroplasty compared to age-matched individuals without knee disability. J Orthop Sports Phys Ther. 1998;27(4):255-63.

23. Lingard EA, Katz JN, Wright EA, Sledge CB. Predicting the outcome of total knee arthroplasty. J Bone Joint Surg. 2004;86(10):2179-86

24. Lützner J, Hartmann A, Lützner C, Kirschner S. Is range of motion after cruciate-retaining total knee arthroplasty influenced by prosthesis design? A prospective randomized trial. J Arthroplast. 2014;29(5):961-5.

25. Bellamy N, Buchanan WW, Goldsmith CH, Campbell J, Stitt LW. Validation study of WOMAC: a health status instrument for measuring clinically important patient relevant outcomes to antirheumatic drug therapy in patients with osteoarthritis of the hip or knee. J Rheumatol. 1988;15(12):1833-40.

26. Collins NJ, Misra D, Felson DT, Crossley KM, Roos EM. Measures of knee function: international knee documentation committee (IKDC) subjective knee evaluation form, knee injury and osteoarthritis outcome score (KOOS), knee injury and osteoarthritis outcome score physical function short form (KOOS-PS), knee outcome survey activities of daily living scale (KOS-ADL), Lysholm knee scoring scale, Oxford knee score (OKS), western Ontario and McMaster universities osteoarthritis index (WOMAC), activity rating scale (ARS), and Tegner activity score (TAS) Arthritis Care Res. 2011;63(S11):S208-28.

27. Gill SD, de Morton NA, Mc Burney $H$. An investigation of the validity of six measures of physical function in people awaiting joint replacement surgery of the hip or knee. Clin Rehabil. 2012;26(10):945-51.
28. Stratford P. Assessing disability and change on individual patients: a report of a patient specific measure. Physiother Can. 1995:47:258-63.

29. Chatman AB, Hyams SP, Neel JM, Binkley JM, Stratford PW, Schomberg A, Stabler M. The patient-specific functional scale: measurement properties in patients with knee dysfunction. Phys Ther. 1997;77(8):820-9.

30. Berghmans DD, Lenssen AF, van Rhijn LW, de Bie RA. The patient-specific functional scale: its reliability and responsiveness in patients undergoing a Total knee arthroplasty. J Orthop Sports Phys Ther. 2015;45(7):550-6.

31. Insall JN, Dorr LD, Scott RD, Scott WN. Rationale of the knee society clinical rating system. Clin Orthop Relat Res. 1989;(248):13-4.

32. Lingard EA, Katz JN, Wright RJ, Wright EA, Sledge CB. Validity and responsiveness of the knee society clinical rating system in comparison with the SF-36 and WOMAC. J Bone Joint Surg. 2001;83-A(12):1856-64.

33. Ware JE Jr, Kosinski M, Keller SD. A 12-item short-form health survey: construction of scales and preliminary tests of reliability and validity. Med Care. 1996;34(3):220-33.

34. Kamper SJ, Ostelo RW, Knol DL, Maher CG, de Vet HC, Hancock MJ. Global perceived effect scales provided reliable assessments of health transition in people with musculoskeletal disorders, but ratings are strongly influenced by current status. J Clin Epidemiol. 2010;63(7):760-766.e761.

35. Drouin JM, Valovich-mcLeod TC, Shultz SJ, Gansneder BM, Perrin DH. Reliability and validity of the Biodex system 3 pro isokinetic dynamometer velocity, torque and position measurements. Eur J Appl Physiol. 2004;91(1):22-9.

36. Lenssen AF, van Dam EM, Crijns YH, Verhey M, Geesink RJ, van den Brandt PA, de Bie RA. Reproducibility of goniometric measurement of the knee in the in-hospital phase following total knee arthroplasty. BMC Musculoskelet Disord. 2007:8:83.

37. Webster KE, Wittwer JE, Feller JA. Validity of the GAITRite walkway system for the measurement of averaged and individual step parameters of gait. Gait Posture. 2005;22(4):317-21.

38. Field AP. Discovering statistics using SPSS: SAGE Publications Ltd; 2009.

39. Ostermeier S, Friesecke C, Fricke S, Hurschler C, Stukenborg-Colsman C. Quadriceps force during knee extension after non-hinged and hinged TKA: an in vitro study. Acta Orthop. 2008;79(1):34-8.

40. Bohannon RW, Andrews AW. Normal walking speed: a descriptive metaanalysis. Physiotherapy. 2011;97(3):182-9.

41. Pua Y-H, Seah FJ-T, Clark RA, Poon CL-L, Tan JW-M, Chong H-C. Factors associated with gait speed recovery after total knee arthroplasty: a longitudinal study. In: Seminars in arthritis and rheumatism: 2017: Elsevier; 2017. p. 544-51.

42. Alnahdi AH, Zeni JA, Snyder-Mackler L. Gait after unilateral total knee arthroplasty: frontal plane analysis. J Orthop Res. 2011;29(5):647-52.

43. Health UDo. Interpreting the SF12. In. 2001:1-17. http://health.utah.gov/ opha/publications/2001hss/sf12/SF12_Interpreting.pdf. Accessed 31 Aug 2017.

Ready to submit your research? Choose BMC and benefit from

- fast, convenient online submission

- thorough peer review by experienced researchers in your field

- rapid publication on acceptance

- support for research data, including large and complex data types

- gold Open Access which fosters wider collaboration and increased citations

- maximum visibility for your research: over $100 \mathrm{M}$ website views per year

At BMC, research is always in progress.

Learn more biomedcentral.com/submissions 